\title{
Re: "Combination of Extracorporeal Shockwave Lithotripsy and Ureteroscopy for Large Staghorn Calculi in a Pediatric Patient: Case Report" by Schults et al. (J Endourol Case Rep 2017;3:64-66)
}

\author{
Cumhur Yesildal, MD, Sinan Kirecci, MD, and Ayhan Dalkiliç, MD
}

$\stackrel{\text { Dear }}{\mathbf{W}}$ Staghorn Calculi in a Pediatric Patient: Case Report", ${ }^{1}$ with great interest. Stone diseases in the pediatric population are an important clinical problem. The diseases are recurrent in nature, and they are generally related to metabolic anomalies. Treatment options are decided based on many parameters: patient's age, stone size and structure, comorbidities, experience of the surgeon, and also patient's choice.

For larger renal stones $(>2 \mathrm{~cm})$, guidelines recommend other treatment modalities rather than extracorporeal shockwave lithotripsy. In this case, Storz/Ge OEC 9800 lithotripter was used. The patient ought to have prolonged duration of therapy, as he had higher radiation exposure. In addition, he had necessitated secondary intervention, a retrograde intrarenal surgery procedure, which needed general anesthesia. It causes more morbidity and is a much higher cost. Also in this case, the patient was infected with proteus mirabilis, and as seen on the kidney, ureter, and bladder radiograph, stone density was low. Those factors preoccupy us with infectious stones. Those stones may harbor bacteria and antibiotic treatment will not be effective. Because of that reason, increased incidence of urosepsis and severe pyelonepritis may occur.

We do not know the surgeon's experience or the family's choice, but in our opinion, and as recommended in the guidelines, percutaneous nephrolithotomy should be considered as a first choice treatment modality because of those factors mentioned above. Also, at onset, a well-informed patient's family is crucial. They should know the advantages and disadvantages of all the treatment modalities. A well-informed patient's family and their informed consent form protects the physician.

\section{Reference}

1. Schults AJ, Jia W, Ost MC, Oottamasathien S. Combination of extracorporeal shockwave lithotripsy and ureteroscopy for large staghorn calculi in a pediatric patient: case report. J Endourol Case Rep 2017;3:64-66.

Address correspondence to:

Cumhur Yesildal

Urology Department

Sissli Hamidiye Etfal Training and Research Hospital Istanbul 34360

Turkiye

E-mail: c_yesildal@hotmail.com

Cite this article as: Yesildal C, Kirecci S, Dalkiliç A (2017) Re: "Combination of extracorporeal shockwave lithotripsy and ureteroscopy for large staghorn calculi in a pediatric patient: case report" by Schults et al. (J Endourol Case Rep 2017;3:64-66), Journal of Endourology Case Reports 3:1, 101, DOI: 10.1089/ cren.2017.0068. 